\title{
The gut is the epicentre of antibiotic resistance
}

\author{
Jean Carlet
}

\begin{abstract}
The gut contains very large numbers of bacteria. Changes in the composition of the gut flora, due in particular to antibiotics, can happen silently, leading to the selection of highly resistant bacteria and Candida species. These resistant organisms may remain for months in the gut of the carrier without causing any symptoms or translocate through the gut epithelium, induce healthcare-associated infections, undergo cross-transmission to other individuals, and cause limited outbreaks. Techniques are available to prevent, detect, and treat the carriage of resistant organisms in the gut. However, evidence on these techniques is scant, the only exception being selective digestive decontamination (SDD), which has been extensively studied in neutropenic and ICU patients. After the destruction of resistant colonizing bacteria, which has been successfully obtained in several studies, the gut could be re-colonized with normal faecal flora or probiotics. Studies are warranted to evaluate this concept.
\end{abstract}

Keywords: Gut, Resistance to antibiotics, SDD, Probiotics, Clostridium difficile, Search, Destroy and restore

Resistance to antibiotics will likely be one of the main public health problems of the next decade [1-4]. Gramnegative bacteria, in particular Enterobacteriaceae, have acquired or selected many genes of resistance in the past few years and are now often resistant to third-generation cephalosporins, since they carry extended-spectrum beta-lactamases (ESBLs)[5]. This mechanism of resistance initially emerged in Klebsiella pneumoniae but is now even more common in Escherichia coli, a microorganism that lives in the human gut, generally in good intelligence with the host [6]. In several countries, community-acquired infections such as pyelonephritis and peritonitis must be treated with carbapenems, our last line of therapy and a class of drugs heretofore reserved for severe nosocomial infections occurring in the intensive care unit (ICU). Some K. pneumoniae and E. coli strains are becoming resistant to carbapenems and require the use of old antibiotics characterized by high toxicity, such as colistin [7]. Resistant Enterobacteriaceae strains are sometimes imported from geographic areas such as Greece, India, North Africa, and Asia [8], in particular after medical tourism. High virulence and resistance may occur in combination, as a lethal duo, as illustrated by the recent outbreak of E. coli 0104-H4

Correspondence: Jeancarlet@gmail.com

Réanimation Polyvalente, Fondation Hopital St Joseph, 185 Rue Raymond Losserand, Paris 75014, France from contaminated sprouts, which chiefly affected Germany [9]. Hospital strains, such as Pseudomonas aeruginosa, Enterobacter spp, and Acinetobacter spp are highly resistant to ceftazidime, carbapenems, and quinolones [10]. Foodborne nosocomial outbreaks with strains producing SHV and CTX-M-15 have also been described [11]. These data indicate a spiral of increasing resistance that will be very difficult to control [1].

Resistance is an ancient phenomenon related to many factors [12] including the excessive use of antibiotics in both human and veterinary medicine $[13,14]$ and crosstransmission of resistant strains from humans to humans and from animals to humans. A recent study [15] identified ESBL-producing E. coli strains in up to $80 \%$ of retail chicken-meat samples in The Netherlands, a country with very low resistance rates in humans until now. Similar strains have been detected in rectal swabs from humans working with animals [16], and consumers are probably at risk for contamination during meal preparation or consumption of insufficiently cooked meat [17].

The increase in ESBL-secreting E. coli strains coincides with a marked decrease in the prevalence of methicillinresistant Staphylococcus aureus (MRSA) in several countries [18], indicating that the mechanisms involved differ and that measures instituted to control MRSA are not sufficient to prevent outbreaks of ESBL-secreting organisms. Gram-negative organisms colonize the immense 
surface area of the human gut. Thus, the amount of susceptible and resistant Enterobacteriaceae in the human body is far greater than the amount of MRSA. Hands can carry high numbers of Gram-negative bacteria [19]. Since compliance with hand disinfection is still very low in many countries [20], cross-transmission can occur easily. In addition, other mechanisms are involved $[12,21]$, such as importation into hospitals of ESBLsecreting $E$. coli from the community. In addition, faeces and contaminated sewage from hospitals and livestock can contaminate river water if no waste processing plant is available. This contaminated water may then be used for watering trees or other plants [22,23].

\section{The gut as the epicentre of bacterial resistance}

Knowledge of the gut microbiome, an extraordinarily complex community of organisms, has improved dramatically since the introduction of metagenomics [24]. Many horizontal gene transfers occur among Enterobacteriaceae $[25,26]$ and between pathogens and the gut flora, most notably when the gut barrier is altered [27]. The resistome is also going to be better understood. Under normal conditions, the gut "receives" a large amount of bacteria from the hands, pharyngeal and nasal secretions, water, food, and beverages. Neonates acquire the environmental flora very quickly after birth [28] and in a few cases develop sepsis after translocation of this new flora [29]. In healthy humans, the gut flora in each individual is surprisingly stable [30], and ingested pathogens are cleared fairly easily due to the presence of the commensal flora composed chiefly of anaerobes, most of which are very difficult to isolate. The ingestion of large inoculums of highly pathogenic bacteria (e.g., Vibrio cholerae, Salmonella spp, or staphylococci) or viruses (e.g., enteroviruses such as echovirus) can destabilise the normal gut microbiome, overwhelm natural defence mechanisms, and induce various clinical symptoms. Antibiotics also very efficiently destabilise the gut microbiome [31-33]. Genetic studies show that even an extremely brief course of antibiotics such as macrolides can induce very long-lived changes in the gut flora, for up to 4 years [34]. Far more will be learned about the gut microbiome in the near future, in particular regarding its stability and alterations.

1) The effect of antibiotics on the digestive flora Most antibiotics exert a dramatically disruptive effect on the gut microbiome [31-33]. Antibiotics very rapidly kill susceptible bacteria, including $E$. coli and the chiefly anaerobic micro-organisms responsible for the barrier function [35]. In parallel, there is an increase in Candida and Pseudomonas species, as well as in Enterococci if a cephalosporin is used [35]. However, depending on the antibiotic, important differences are observed [35]. Antibiotics can select gut micro-organisms initially present in very small amounts, such as Clostridium difficile, ESBLsecreting E. coli (up to $6 \%$ of normal individuals are colonised in France [36]), P. aeruginosa, Candida spp, or even Acinetobacter spp $[37,38]$. Collateral damage is worse with antibiotics that have a broad spectrum and/or are largely eliminated via the bile and gut (e.g., ceftriaxone) [39]. In theory, regulatory agencies require an evaluation of the impact of new antibiotics on the gut before granting marketing licences.

2) The gut in critically ill patients The gut epithelium is very fragile and can be profoundly altered in the most severely ill ICU patients. An increase in gut permeability allows the translocation of micro-organisms into the bloodstream with bacteraemia or candidaemia. Endotoxins and other toxins can also cross the gut barrier. Bacteraemia and endotoxinaemia are among the mechanisms involved in severe sepsis and multiple organ failure [40].

Colonisation of the oro-pharynx, stomach, and distal gut with resistant micro-organisms (enterococci, staphylococci, and Gram-negative bacteria such as $P$. aeruginosa) happens very quickly, especially in patients treated with antibiotics. Resistant organisms may be present in very large amounts and are not efficiently cleared from the gut, as transit is often extremely slow. Thus, the gut of ICU patients can be likened to a bacteriological time bomb. The "new" flora (secondary endogenous) [41] can be responsible for nosocomial infections. For instance, gut organisms introduced into the oro-pharyngeal and nasal cavities by gastro-oesophageal reflux may then be inhaled, causing ventilator-associated pneumonia (VAP). This mechanism is the rationale for the use of selective digestive decontamination (SDD) in ICU patients [42].

3) Health-care associated infections with resistant bacteria: where do the bacteria come from? Resistance to antibiotics can occur in foci of infection during antibiotic therapy (e.g., in the lung in ICU patients treated for VAP) or in the commensal flora, most notably in the gut. Selection of resistant micro-organisms may occur in the gut even after successful treatment of the primary focus of infection [43]. During broad-spectrum antibiotic therapy, the gut may contain high concentrations of most of the resistant Gram-negative and -positive bacteria, including not only Enterobacteriaceae, but also Pseudomonas, Acinetobacter [37,38], vancomycin-resistant enterococci (VRE), and sometimes even MRSA [44]. Most of the time, these 
organisms do not result in clinical symptoms and their presence is therefore overlooked. In the most severely ill patients (often in the ICU) and in neutropenic patients, some of the gut microorganisms (chiefly those present in large amounts) can induce healthcare-associated infections such as pneumonia or translocate through the gut barrier, inducing bacteraemia and/or candidaemia. Lifethreatening sepsis may develop as a result in the most severely immunocompromised or neutropenic patients [45].

4) Risk of cross-transmission of gut micro-organisms The risk of dissemination of multi-resistant Gram-negative bacteria coming from the gut is probably very high, particularly in the ICU [19], since bacteria are found in high concentrations in the rectum. The faeces may contain huge amounts of bacteria $\left(10^{8}\right.$ per gram of faeces or more), which can then be transmitted via the hands. However, this topic requires more information, since crosstransmission of ESBL-producing $E$ coli seems rather limited [46]. Risk factors for dissemination include dependency for toileting, diarrhoea, and living in countries where hygiene is poor. Furthermore, in long-term care facilities, infection control measures are more difficult to implement than in acute care settings.

The very low compliance with hand hygiene rules in most hospitals [47] is a major obstacle to preventing the cross-transmission of resistant and susceptible micro-organisms. Life in hospitals and in the community comprises a succession of small mistakes, which usually have little impact but may increase the risk of cross-transmitting resistant micro-organisms. For example, hand washing after defecation is performed inefficiently or not at all by many individuals. Even in industrialised countries, many people are unaware of the need to decontaminate the hands before and after certain activities. For instance, the hands should be washed thoroughly before touching the clothes and door handles, which requires that a sink be available in the toilet. Simple educational programs designed for the general public are needed. Targeting children may be particularly efficient, as children can then educate the adults in their family [48]. For healthcare professionals in hospitals, alcohol hand rubs or proper use of gloves are very helpful [49]. Contamination and colonisation may also be related to environmental contamination in hospitals, possibly with variations across Gram-negative bacteria [46]. In addition, multi-drug-resistant organisms (MDROs) may be ingested with water or food in the community $[23,50,51]$.

\section{Are there methods to prevent or treat gut colonisation with resistant gram-negative bacteria?}

Although several methods have been discussed, the available information is scant and controversial. Efforts to control bacterial resistance can consist in either prevention or treatment.

1) Oral digestive decontamination for preventing nosocomial infections and antibiotic resistance SDD has been used chiefly in patients with haematological diseases or neutropenia [52] and in ICU patients, with some measure of success, particularly regarding the incidence of bacteraemia and VAP [53]. The initial goals were to decrease early-onset infections, secondary endogenous colonisation, and the gut endotoxin content. SDD relies on non-absorbable antibiotics (aminoglycosides, polymyxin E, and amphotericin B) applied to the oro-pharyngeal cavity and administered into the stomach, usually in combination with an intravenous antibiotic (thirdgeneration cephalosporin) for three days. The use of SDD was highly controversial at first, chiefly because early studies found no significant decrease in mortality [53] and many physicians were deeply concerned about the risk of selecting organisms resistant to the drugs used for SDD [54-56],. Recent studies, however, documented a significant decrease in mortality $[55,57,58]$ and a paradoxical decrease in resistance to the antibiotics used locally or systemically $[55,58]$. Additional studies are clearly needed, since the effect of SDD might be greatly influenced by the level of resistance in a given country $[55,58]$. It should be noted that the follow up of the studies is relatively short. In summary, SDD has been convincingly proven to decrease the incidence of VAP in the ICU, which is likely to explain the improvement in patient survival. The effect of SDD on antibiotic resistance should be studied in multicentre international studies with a long follow-up. There is now considerable reluctance to use colistin for prevention, as this antibiotic may be the only drug that remains effective to treat some patients with multiple-resistant Gram-negatives.

2) Probiotics

Probiotics have been suggested to maintain or restore gut homeostasis. Probiotics are defined by the World Health Organisation as 'live microorganisms which when administered in adequate amounts confer a health benefit on the host'. Lactic acid bacteria and bifidobacteria are the most common micro-organism types used as probiotics, although certain yeasts and bacilli may 
also be helpful. Saccharomyces boulardii is a tropical yeast which has been shown to maintain and restore the natural flora in the large and small intestine [59] and is classified as a probiotic. Non-pathogenic E. coli strains such as Nissle $1917(\mathrm{EcN})$ are also classified as probiotics and have been studied in animals, normal volunteers, and elderly patients [60-64].

Studies of S. boulardii treatment have generated highly conflicting results. S. boulardii has been reported to enter the bloodstream in patients with altered gut permeability or marked neutropenia [65]. Studies found that $S$. boulardii administration decreased VAP rates [66] and recurrences of C. difficile infections [67]. A major anti-inflammatory effect in patients with gastrointestinal tract infections or inflammatory bowel diseases was documented in numerous studies.

Many other probiotics have been studied, most notably Lactobacillus, alone or in combination with other probiotics. Apart from effects in gastrointestinal diseases, some studies showed a decrease in VAP, although the results were conflicting [68]. The effects of E. coli Nissle 1917 (EcN) are similarly unclear. Studies in piglets showed effects on the microbiome and EcN persistence in the gut $[60,61]$. Persistence of EcN in the faeces was demonstrated in healthy volunteers [62,63]. However, a randomised double-blind study in 69 elderly carriers of quinolone-resistant $E$. coli showed no difference with the placebo regarding the persistence of quinoloneresistant strains in the faeces during therapy [64]. Whether probiotics can prevent or treat multi-drug resistant organisms ( $\mathrm{MDRO}$ ) colonisation remains unknown.

3) Antibiotics with local effects for managing outbreaks Targeting resistant bacteria with non-absorbable antibiotics is an extremely appealing strategy that has been investigated in patients carrying multi-resistant strains, as well as during outbreaks. Brun-Buisson et al. [69] controlled an ESBL-producing K. pneumoniae outbreak in the ICU using a combination of colistin and gentamicin. Oro-pharyngeal chlorhexidine baths combined with oral paromomycin (plus an oral antibiotic in patients with urinary tract colonisation/infection) was effective in $76 \%$ of patients carrying ESBL-producing E. coli or K. pneumoniae [70]. More recently, Perez et al. [71] and Saide-Odes et al. [72] showed in mice and humans, respectively, that polymyxin E plus gentamicin was effective against KPC-producing $K$. pneumoniae carriage. Similar efficacy was reported against Acinetobacter [73]. Oostdiijk et al. established the efficacy of SDD in eradicating cephalosporin- resistant Enterobacteriaceae from the gut [74]. The data are relatively convincing. However, follow-up is relatively short in all the available studies, and it is difficult to know if recurrences and long term persistence could happen.

4) Faecal microbiome transplantation

Faecal microbiome transplantation consists in administering faecal flora from a normal individual into the gut of a patient with the goal of achieving colonisation with a well-balanced community of organisms. Faecal microbiome transplantation has produced excellent results in patients with $C$. difficile relapses [75-77]. In two recent systematic reviews, faecal microbiome transplantation via the oral route or colonoscopy was effective in $83 \%$ and $92 \%$ of cases of $C$. difficile disease, respectively $[75,76]$. Only 317 patients were treated in all, and the studies were mostly case-series with no control groups. Similar positive results were obtained in young infants with C. difficile resistant to S. boulardii and Lactobacillus rhamnosus, as well as to many antibiotics [59]. The effect of transplanting $E$. coli, instead of the entire normal gut microbiome, has not been widely studied in humans [46-48], and the data are conflicting. Positive results were obtained in animals, particularly mice [78]. Additional studies are needed, both in C. difficile infections and in other conditions. It would be of great interest to determine whether faecal microbiome transplantation prevents MDRO re-colonisation after decolonisation.

5) Beta-lactamase treatment

Oral treatment with enteric-coated beta-lactamases has been used in dogs and in humans $[79,80]$ in an attempt to prevent the appearance of antibiotic resistance in the gut during intravenous ampicillin administration. The desired effect is destruction by the beta-lactamase of residual antibiotic in the distal gut, to prevent the acquisition of resistance without affecting systemic drug levels. Both studies were encouraging, in particular the study in human patients, which included a control group $[79,80]$. However, the development of this compound has been stopped due to a lack of resources. This topic deserves further attention, since the concept is appealing.

6) The search, destroy, and restore concept The 'search and destroy' concept was used initially in The Netherlands to prevent and treat MRSA colonisation and infection. Patients at risk for MRSA carriage were screened, and cultures of the pharynx and sometimes of the skin were performed [81]. The patients were isolated until the results became negative. Patients with MRSA colonisation were treated with nasal mupirocin, often combined with 
chlorhexidine baths. This strategy may be among the reasons explaining the very low prevalence of MRSA in The Netherlands [64]. The search and destroy strategy has also produced favourable outcomes in Ireland, Denmark, and other Scandinavian countries $[82,83]$. Similar strategies are now used more widely not only for MRSA, but also for resistant Gram-negative bacteria producing ESBL or carbapenemases [69-74]. At-risk patients (coming from high-prevalence countries or having had numerous hospital stays) are screened then isolated until the results are available. No official guidelines have been issued for treating colonised patients. Decolonisation was achieved in a few studies [69-74].

It would seem logical to add a third step after the search and destroy steps, consisting in gut recolonisation with normal flora or E. coli. This search, destroy, and restore strategy would be expected to decrease the risk of re-colonisation with MDROs [84]. Studies of this strategy are warranted. Several methods could be evaluated, including the administration of probiotics and faecal microbiome transplantation.

\section{Conclusion}

The gut plays a prominent role in the development of antibiotic resistance, allowing the hidden selection and multiplication of resistant micro-organisms in the community, long-term care facilities, and hospitals [84]. The emergence of resistant micro-organisms in the gut may be related to the ingestion of highly pathogenic microorganisms or to antibiotic-induced alterations in the gut microbiome [85]. The resistant organisms then contaminate the environment via the faeces [86]. Crosstransmission of the resistant strains can occur relatively easily if strong hygiene measures are not taken. However, these measures are not easy to implement [87].

Methods for preventing or controlling the appearance of antibiotic resistance in the gut include SDD, local antibiotic therapy, probiotics, and elimination of residual antibiotics from the gut (using enzymes or adsorbents). Studies are warranted to determine whether combining several of these methods in a search, destroy and restore strategy is effective and safe. The available data on the gut as a reservoir for antibiotic resistance are uncomplete, and much more will have to be learned before recommendations are made.

\section{Competing interests}

Dr Jean Carlet is a consultant for da Voltera, Biomérieux, Thermofisher, AstraZeneca, Astellas, and Aromatechnologies.

Received: 15 July 2012 Accepted: 19 November 2012

Published: 27 November 2012

\section{References}

1. Carlet J, Collignon P, Goldmann P, et al: Society's failure to protect a precious resource: antibiotics. Lancet 2011, 378:369-371.

2. Hughes JM: Preserving the lifesaving power of antimicrobial agents. Jama 2011, 305:1027-1028.

3. Piddock $\sqcup$ : The crisis of no new antibiotics-what is the way forward. Lancet Infect Dis 2012, 12:24953.

4. Bush $\mathrm{K}$, Courvalin P, Gautam D, et al: Tackling antibiotic resistance. Nature reviews/microbiology 2011, 9:894-895.

5. Lowe CF, McGeer A, Muller MP, Katz K, for the Toronto ESBL working group: Decreased susceptibility to non-carbapenem antimicrobials in extendedspectrum-B-lactamase-producing Escherichia coli and Klebsiella pneumoniae isolates in Toronto, Canada. Antimicrob Agents Chemother 2012, 56:3977-3980

6. Baquero F, Alvarez-Ortega C, Martinez JL: Ecology and evolution of antibiotic resistance. Envoron Microbial Reports 2009, 1:469-476.

7. Canton R, Akova M, Carmeli Y, et al: Rapid evolution and spread of carbapenemases among enterobacteriaceae in Europe. Cli Microbiol Infect 2012, 18:413-431.

8. Gupta N, Limbago BM, Patel JB, Kallen AJ: Carbapenem-resistant Enterobacteriaceae: epidemiology and prevention. Clin Infect Dis 2011, 53:60-67.

9. Bochholz U, Werber D, Bohmer MM, et al: German outbreak of Escherichia coli 0104:H4 associated with sprouts. N Engl J Med 2011, 365:1763-1770.

10. European Centre for Disease Prevention and Control: EARSS net database. http://ecdc.europa.eu.

11. Calbo E, Freixas N, Xercavins M, et al: Foodborne nosocomial outbreak of SHV1 and CTX-M-15-producing Klebsiella pneumoniae: epidemiology and control. Clin Infect Dis 2011, 52:743-749.

12. D'Costa VM, King CE, Kalan $L$, et al: Antibiotic resistance is ancient. Nature 2011, 477:457-461.

13. Levy SB: Microbial resistance to antibiotics. An evolving and persistent problem. Lancet 1982, 2:83-88.

14. Hecker MT, Aron DC, Patel NP, Leymann MK, Donskey CJ: Unnecessary use of antimicrobials in hospitalized patients: current patterns of misuse with an emphasis on the antianaerobic spectrum of activity. Arch Intern Med 2003, 163:972-978.

15. Overdevest I, Willemsen I, Rijnsburger $M$, et al: Extended-spectrum $\beta$ lactamase genes of Escherichia coli in chicken meat and humans, the Netherlands. Emerg Infect Dis 2011, 17:1216-1222.

16. Leverstein-van Hall MA, Dierihx CM, Cohen Stuart J, et al: Dutch patients, retail chicken meat and poultry share the same ESBL genes, plasmids and strains. Clin Microbial Infect 2011, 17:873-880.

17. Vieira AR, Collignon P, Aarestrup FM, et al: Association between antimicrobial resistance in Escherichia coli isolates from food animals and bloodstream isolates from humans in Europe: an ecological study. Foodborne Pathog Dis 2011, 8:1295-1301.

18. Jarlier V, Trystram D, Brun-Buisson C, et al: Curbing methicillin resistant Staphylococcus aureus in 38 French hospitals through a 15-year institutional program. Arch Intern Med 2010, 170:552-559.

19. Cipolla $D$, Giuffrè M, Mammina C, Corsello L: Prevention of nosocomial infections and surveillance of emerging resistances in NICU. J Matern Fetal Neonatal Med 2011, 24(1):23-26.

20. Allegranzi B, Storr J, Dziekan G, et al: The first global patient challenge "Clean care is safer care": from the lunch to current progress and achievements. J Hosp Infect 2007, 65(suppl 2):115-123.

21. Forstberg KJ, Reyes A, Wang B, et al: The shared antibiotic resistome of soil bacteria and human pathogens. Science 2012, 337:1107-1111.

22. Allen HK, Donato J, Wang HU, et al: Call of the wild: antibiotic resistance genes in natural environments. Nature Reviews/Microbiology 2010, 8:251-259.

23. Tello A, Austin B, Telfer TC: Selective pressure of antibiotic pollution on bacteria of importance to public health. Environ Health Perspect 2012, 120:1100-1106.

24. Peterson J, Garges S, Giovanni M, et al: The NIH human microbiome project. Genome Res 2009, 19:2317-2323.

25. Cremet L, Bourigault C, Lepelletier D, et al: Nosocomial outbreak of carbapenem-resistant Enterobacter cloacae highlighting the interspecies transferability of the blaOXA-48 gene in the gut flora. J Antimicrob Chemother 2012, 67:1041-1043. 
26. Schjorring S, Krogfelt KA: Assessment of bacterial antibiotic resistance transfer in the gut. Int J Microbiol 2011, 2011:312956.

27. Stecher B, Denzler R, Maier $L$, et al: Gut inflammation can boost horizontal gene transfer between pathogenic and commensal Enterobacteriaceae. Proc Natl Acad Sci USA 2012, 109:1269-1274

28. Guarino A, Wudy A, Basile F, Ruberto E, Buccigrossi V: Composition and roles of intestinal microbiota in children. J Matern Fetal Neonatal Med 2012, 25(Suppl 1):63-66.

29. Das $P$, Singh AK, Pal T, et al: Colonization of the gut with Gram-negative bacilli, its association with neonatal sepsis and its clinical relevance in a developing country. J Med Microbiol 2011, 60:1651-1660.

30. Tezuka H, Ohteki T: Regulation of intestinal homeostasis by dendritic cells. Immunol Rev 2010, 234:247-258.

31. Cremieux AC, Muller-Serieys C, Panhard X, et al: Emergence of resistance in normal human aerobic commensal flora during telithromycin and amoxicillin-clavulanic acid treatments. Antimicrobiol Agents Chemother 2003, 47:2030-2035.

32. Jemberg C, Loffmark S, Edlund C, Jansson J: Long-term impacts of antibiotic exposure on the human intestinal microbiota. Microbiology 2010, 156:3216-3223

33. Jeong SH, Song YK, Cho JH: Risk assessment of ciprofloxacin, flavomycin, olaquindox and colistin sulfate based on microbiological impact on human biota. Regul Toxicol Pharmacol 2009, 53:209-216.

34. Jakobsson HE, Jemberg C, Andersson AF, et al: Short-term antibiotic treatment has differing long-term impacts on the human throat and gut microbiome. Plos One 2010, 5:e 9836.

35. Donskey CJ, Chowdhry TK, Hecker MT, et al: Effect of antibiotic therapy on the density of vancomycin-resistant enterococci in the stool of colonized patients. N Engl J Med 2000, 343:1925-1932.

36. Nicolas-Chanoine MH, Gruson C, Bialek-Davenet S, et al: 10-fold increase $(2006-11)$ in the rate of healthy subjects with extended-spectrum B-lactamase-producing Escherichia coli faecal carriage in a Parisian check-up centre. J Antimicrob Chemother 2012, November 9 Epub ahead of print

37. Timsit JF, Garrait V, Misset B, et al: The digestive tract as a major site for Acinetobacter baumannii colonization in intensive care unit patients. $J$ Infect Dis 1993, 168:1336-1337.

38. Thom KA, Hsiao WW, Harris AD: Patients with Acinetobacter baumannii bloodstream infections are colonized in the gastrointestinal tract with identical strains. Am J Infect Control 2010, 38:751-753.

39. Goldstein EJ: Beyond the target pathogen: ecological effects of the hospital formulary. Curr Opin Infect Dis 2011, 24(Suppl 1):S21-31.

40. Taneja R, Marshall JC: Vasoactive agents and the gut: fueling the motor of multiple organ failure. Crit Care Med 2000, 28:3017-3018.

41. van Uffelen $R$, van Saene HK, Fidler V, Löwenberg A: Oropharyngeal flora as a source of bacteria colonizing the lower airways in patients on artificial ventilation. Intensive Care Med 1984, 10:233-237.

42. Stoutenbeek CP, van Saene HK, Miranda DR, Zandstra DF: A new technique of infection prevention in the intensive care unit by selective digestive decontamination of the digestive tract. Acta Anaesthegiol Belg 1983, 34:209-221.

43. Kesteman AS, Perrin-Guyomard A, Laurenti M, et al: Emergence of resistant Klebsiella pneumoniae in the intestinal tract during successful treatment of Klebsiella pneumoniae lug infection in rats. Antimicrob Agents Chemother 2010, 54:2960-2964.

44. Lemmens N, van Wamel W, Snijders S, et al: Genomic comparisons of USA 333 Staphylococcus aureus colonizing the nose and rectum in children with skin abscesses. Microbiol Pathog 2011, 50:192-199.

45. Uramatsu M, Matsumoto $T$, Shibuya $K$, et al: Involvement of endotoxin in the mortality of mice with gut-derived sepsis due to methicillin-resistant Staphylococcus aureus. Microbiol Immunol 2010, 54:330-337.

46. Guet-Revillet $\mathrm{H}$, Le Monnier A, Breton N, et al: Environmental contamination with extended-spectrum $\beta$-lactamases: is there a difference between Escherichia coli and Klebsiella spp? Am J Infect Control 2012, 40:845-848.

47. Stewardson A, Allegranzi B, Sax H, Kilpatrick C, Pittet D: Back to the future: rising to the Semmelweis challenge in hand hygiene. Future Microbiol 2011, 6:855-876.

48. Lecky DM, McNulty CA, Adriaenssens N: Development of an educational resource on microbes, hygiene and prudent antibiotic use for junior and senior school children. J Antimicrobial Chemother 2011, 66(Suppl 5):23-31.
49. Sax H, Allegranzi B, Uckay l, et al: 'My five moments for hand hygiene': a user-centred design approach to understand, train, monitor and report hand hygiene. J Hosp Infect 2007, 67:9-21.

50. Kumarasamy KK, Toleman MA, Walsh TR, et al: Emergence of a new antibiotic resistance mechanism in India, Pakistan, and the UK. A molecular, biological and epidemiological study. Lancet Infect Dis 2010, 10:597-602

51. Loofts T, Johnson TA, Allen HK, et al: In-feed antibiotic effects on the swine intestinal microbiome. Proc Natl Acad Sci USA 2012, 109:1691-1696.

52. De Vries-Hospers HG, Sleifer DT, Mulder NH, et al: Bacteriological aspects of selective decontamination of the digestive tract as a method in infection prevention in granulocytopenic patients. Antimicrob Agents Chemother 1981, 19:813-820.

53. Stoutenbeek CP, van Saene HK, Miranda DR, Zandstra DF: The effect of selective decontamination of the digestive tract on colonization and infection rate in multiple trauma patients. Intensive Care Med 1984, 10:185-192

54. Al-Naemi N, Heddema ER, Bart A, et al: Emergence of multidrug-resistant Gram-negative bacteria during selective decontamination of the digestive tract on an intensive care unit. J Antimicrob Chemother 2006, 58:853-856

55. De Smet AM, Kluytmans JA, Blok HE, et al: Selective digestive tract decontamination and selective oropharyngeal decontamination and antibiotic resistance in patients in intensive-care units: an open-label clustered group-randomised, crossover study. Lancet Infect Dis 2011, 11:372-380

56. Ochoa-Ardila ME, Garcia-canas A, Gomez-Mediavilla K, et al: Long term use of selective decontamination of the digestive tract does not increase antibiotic resistance: a 5-year prospective cohort study. Intensive Care Med 2011, 37:1458-1465

57. De Smet AM, Kluytmans JA, Cooper BS, et al: Decontamination of the digestive tract and oropharynx in ICU patients. N Engl J Med 2009, 360:20-31.

58. De Jonge E, Schultz MJ, Spaniaard L, et al: Effect of selective decontamination of digestive tract on mortality and acquisition of resistant bacteria in intensive care: a randomized controlled trial. Lancet 2003, 362:1011-1016.

59. Guandalini S: Probiotics for prevention and treatment of diarrhea. J Clin Gastroenterol 2011, 45(Suppl):S149-153.

60. Barth S, Duncker S, Hempe J, et al: Escherichia coli Nissle 1917 for probiotic use in piglets: evidence for intestinal colonization. J Applied Microbiol 2009, 107:1697-1710.

61. Prilassnig M, Wenisch C, Daxboeck F, Feierl G: Are probiotics detectable in human feces after oral uptake by healthy volonteers? Wien Klin Wochenschr 2007, 119:456-462.

62. Joares-Nguyen-Xuan TH, Boehm SK, Joares $L$, et al: Survival of the probiotic Escherichia coli Nissle 1917 (EcN) in the gastrointestinal tract given in combination with oral mesalamine to healthy volunteers. Inflamm Bowel Dis 2010, 16:256-262.

63. Smajs D, Bures J, Chaloupkova E, et al: Experimental administration of the probiotic Escherichia coli strain Nissle 1917 results in decreased diversity of E. coli strains in pigs. Curr Microbiol 2012, 64:205-210.

64. Tannock GW, Tiong IS, Priest P, et al: Testing probiotic strain Escherichia coli Nissle 1917 (Mutaflor) for its ability to reduce carriage of multidrugresistant E. coli by elderly residents in long-term care facilities. J Med Microbiol 2011, 60:366-370.

65. Herbrecht R, Nivoix Y: Saccharomyces cerevisiae fungemia: and adverse effect of Saccharomyces boulardii probiotic administration. Clin Infect Dis 2005, 40:1635-1637.

66. Morrow LE, Goginari V, Malesker MA: Probiotic, Prebiotic, and symbiotic in critically ill patients. Curr Opin Crit Care 2012, 18:91.

67. Na X, Kelly C: Probiotics in Clostridium difficile infection. J Clin Gastroenterol 2011, 45:168-71.

68. Silvestri L, van Saene HK, Gregori D, et al: Probiotics to prevent ventilatorassociated pneumonia: no robust evidence from randomized controlled trial. Crit Care Med 2010, 38:1616-1617.

69. Brun Buisson C, Legrand P, Rauss A, et al: Intestinal decontamination for control of nosocomial multi-resistant gram-negative bacilli. Study of an outbreak in an intensive care unit. Ann Intern Med 1989, 110:873-881. 
70. Buehlmann M, Bruderer T, Frei R, Widemer AF: Effectiveness of a new decolonization regimen for eradication of extended-spectrum B-lactamase-producing Enterobacteriaceae. J Hosp Infect 2011, 77:113-117.

71. Perez F, Pultz M, Endimiani A, Bonomo RA, Donskey CJ: Effect of antibiotic treatment on establishment and elimination of intestinal colonization by KPC-producing Klebsiella pneumoniae in mice. Antimicrob Agents Chemother 2011, 55:2585-2589.

72. Saides-Odes $L$, Polachek $H$, Peled N, et al: A randomized, double-blind, placebo-controlled trial of selective digestive decontamination using oral gentamicin and oral polymyxin E for eradication of carbapenemresistant Klebsiella pneumoniae carriage. Infect Control Hosp Epidemiol 2012, 33:14-19.

73. Agusti C, Pujol M, Argerich MJ, et al: Short term effect of the application of selective decontamination of the digestive tract on different body site reservoir ICU patients colonized by multi-resistant Acinetobacter baumanii. J Antimicrobial Chemother 2002, 49:205-208.

74. Oostdijk EA, de Smet AM, Kesecioglu J, Bonten MJ, Dutch SOD-SDD trialist group: Decontamination of cephalosporin-resistant Enterobacteriaceae during selective digestive decontamination in intensive care units. J Antimicrob Chemother 2012, 67:2250-2253.

75. Gough E, Shaikh H, Manges AR: Systematic review of intestinal mocrobiota transplantation (fecal bacteriotherapy) for recurrent Clostridium difficile infection. Clin Infect Dis 2011, 53:994-1002.

76. Guo B, Harstall C, Louie T, et al: Systematic review: fecal transplantation for the treatment of Clostridium difficile-associated disease. Aliment Pharmad Ther 2012, 35:865-875.

77. Russel G, Kaplan J, Ferraro M, Michelow IC: Fecal bacteriotherapy for relapsing Clostridium difficile infection in a child: a proposed treatment protocol. Pediatrics 2010, 126:239-242.

78. Rosales-Mendoza S, Soria-Guerra RE, Lopez-Revilla R, Moreno-Fieros L, Alpuche-Solis AG: Ingestion of transgenic carrots expressing the Escherichia coli heat-labile enterotoxin B subunit protects mice against cholera toxin challenge. Plant Cell Rep 2008, 27:79-84.

79. Harmoinen J, Mentula S, Heikkila M, et al: Orally administered targeted recombinant B-lactamase prevents ampicillin-induced selective pressure on the gut microbiota: a novel approach to reducing antibacterial resistance. Antimicrob Agents Chemother 2004, 48:75-79.

80. Tarkkanen AM, Heinonen $\mathrm{T}$, Jogi $\mathrm{R}$, et al: P1A recombinant B-lactamase prevents emergence of antimicrobial resistance in gut microflora of healthy subjects during intra-venous administration of ampicillin. Antimicrob Agents Chemother 2009, 53:2455-2462.

81. Vos MC, Behrendt MD, Melles DC, et al: Five years of experience implementing a methicillin-resistant Staphylococcus aureus search and destroy policy at the largest University Medical Center in the Netherlands. Infect Control Hosp Epidemiol 2009, 30:977-984.

82. Bocher S, Skov RL, Knudsen MA, et al: The search and destroy strategy prevents spread and long-term carriage of methicillin-resistant Staphylococcus aureus: results from the follow-up screening of a large ST22 (E-MRSA 15) outbreak in Denmark. Clin Microbiol Infect 2010, 16:1427-1434

83. Higgins A, Lynch M, Gethin G: Can "search and destroy" reduce nosocomial methicillin-resistant Staphylococcus aureus in an Irish hospital. J Hosp Infect 2010, 75:120-123.

84. Tosh PK, McDonald LC: Infection control in the multidrug-resistant era: tending the human microbiome. Clin Infect Dis 2012, 54:707-713.

85. Blaser M: Stop the killing of beneficial bacteria. Nature 2012, 476:393-394.

86. Thevenon F, Agatte T, Widdi W, Poté J: Antibiotic resistant bacteria/genes dissemination in lacustrine sediments highly increased following cultural eutrophication of Lake Geneva (Switzerland). Chemosphere 2012, 86:468-476.

87. Schwaber MJ, Lev B, Israeli A, et al: Containment of a country wide outbreak of carbapenem-resistant Klebsiella pneumoniae in Israeli hospitals via a nationally implemented intervention. Clin Infect Dis 2011, 52:848-855

doi:10.1186/2047-2994-1-39

Cite this article as: Carlet: The gut is the epicentre of antibiotic resistance. Antimicrobial Resistance and Infection Control 2012 1:39.

\section{Submit your next manuscript to BioMed Central and take full advantage of:}

- Convenient online submission

- Thorough peer review

- No space constraints or color figure charges

- Immediate publication on acceptance

- Inclusion in PubMed, CAS, Scopus and Google Scholar

- Research which is freely available for redistribution 